\title{
Extreme sulphur and iron isotope fractionation in pyrites from Cretaceous sediments, Central Apennines, Italy
}

\author{
T. GYOMLAI ${ }^{1,2}$, M. FAYEK ${ }^{2}$, V. FERRINI $I^{3}$, S.
} MIGNARDI $^{3}$, AND C. DE VITO ${ }^{3}$

${ }^{1}$ Institut des Sciences de la Terre de Paris, Sorbonne Université, 4 place Jussieu, 75231 Paris cedex 05, France 2 Department of Geological Sciences, University of Manitoba, Winnipeg, MB R3T 2N2, Canada

${ }^{3}$ Dipartimento di Scienze della Terra, Universita' 'La

Sapienza', P.le A. Moro 5, 00185 Rome, Italy

Sulfides have been used to constrain the diagenetic history of sedimentary rocks, and paleoenvironmental conditions of the Earth's ocean and atmosphere over geological time-scales. Here we present coupled sulfur and iron isotopic compositions in pyrites from 90 Ma limestone sediments from the Poggio Sannita area, Italy, that have some of the highest and lowest reported $\delta^{34} \mathrm{~S}$ and $\delta^{56} \mathrm{Fe}$ values, respectively.

The Poggio Sannita area is located $200 \mathrm{~km}$ SE of Rome and is part of the Apennines orogenic belt. This area is composed by Mesozoic and Cenozoic sediments deposited in the southern Tethys ocean. The Cretaceous limestones from this region comprise of pyrite-bearing sediments with planktonic foraminifera and macrofossils, and bioturbated, fine-grained laminated packstone, devoid of pyrite.

Sulfur and iron isotopic analysis of pyrites from the sulphide-bearing units using secondary ion mass spectrometry show: (1) a large range in $\delta^{34} \mathrm{~S}$ and $\delta^{56} \mathrm{Fe}$ values $(+50$ to $+90 \%$ and -4.7 to $-1.2 \%$, respectively); (2) the considerable micro-scale variations in the $\delta^{34} \mathrm{~S}$ and $\delta^{56} \mathrm{Fe}$ values (up to $40 \%$ and $2 \%$, respectively ); (3) unusually high $\delta^{34} \mathrm{~S}$ values without a corresponding pool of low $\delta^{34} \mathrm{~S}$ values and unusually low $\delta^{56} \mathrm{Fe}$ values without a corresponding pool of high $\delta^{56} \mathrm{Fe}$ values that would be expected from closed-system Rayleigh fractionation. These $\sim 90 \mathrm{Ma}$, pyrites also have $\Delta^{33} \mathrm{~S}$ values that show MIF, which cannot be explained either by $\mathrm{SO}_{2}$ photochemical reduction under UV radiation or hightemperature reactions of sulfate in solution with reactive organic compounds. These extreme isotopic compositions were likely due to the formation of light $\mathrm{Fe}^{2+}$ aq by DIR in the shelf sediments, the transportation of $\mathrm{Fe}^{2+}$ via an iron shuttle, production of heavy $\mathrm{SO}_{4}$ by pyrite precipitation in the water column, diffusion and advection of $\mathrm{SO}_{4}$ and $\mathrm{H}_{2} \mathrm{~S}$, and finally BSR. 